\title{
Gated SPECT in left bundle branch block: from improved diagnosis to improved treatment
}

\author{
E. E. van der Wall $\cdot$ J. J. Bax $\cdot$ J. W. Jukema \\ M. J. Schalij
}

Published online: 15 October 2008

(C) The Author(s) 2008. This article is published with open access at Springerlink.com

Noninvasive detection of myocardial ischemia in patients with left bundle branch block (LBBB) remains a challenge [1,2]. The condition is often associated with coronary artery disease or hypertension, but frequently there is no indication of cardiovascular disease. Exercise-induced electrocardiographic ST-segment changes are non-diagnostic. Myocardial perfusion scintigraphy has been widely used in LBBB patients whereby anteroseptal defects have been observed in the absence of significant left anterior descending (LAD) coronary artery disease [3-5]. Several mechanisms have been proposed to explain this false-positive phenomenon such as metabolic alterations, cardiomyopathic changes, altered relaxation due to abnormal conduction, changes in septal wall motion, reduced septal wall thickening, and redistribution of coronary perfusion [6-10]. Generally, irreversible perfusion defects in the anteroseptal wall and apex are caused by a constant, stress-independent mechanism, whereas reversible defects may indicate underlying ischemia induced by a significant LAD stenosis. The major challenge in LBBB patients remains, however, to discriminate between artifactual septal defects and true ischemic defects. Various interpretative methods and stress

E. E. van der Wall ( $₫)$. J. J. Bax · J. W. Jukema •

M. J. Schalij

Department of Cardiology, Leiden University Medical Center, Albinusdreef 2, 2333 ZA Leiden, The Netherlands

e-mail: e.e.van_der_wall@lumc.nl techniques have been evaluated in an attempt to improve the specificity of noninvasive studies for detecting LAD disease in LBBB patients [11]. The application of pharmacologic stress has resulted in higher specificity than conventional exercise scintigraphy because of a more uniform exploitation of coronary flow reserve [12]. Recently gated myocardial SPECT imaging has been applied to elicit the underlying mechanisms of perfusion abnormalities in patients with LBBB [13-16]. Bavelaar-Croon et al. [14] studied 37 LBBB patients without a history of a previous myocardial infarction who underwent technetium-99 $\mathrm{m}$ tetrofosmin gated SPECT imaging. There was no correlation between perfusion and function in the septum, but a good correlation between perfusion and function in the remote segments, implying that patients with LBBB without a previous myocardial infarction show cardiomyopathic changes with perfusion and wall motion abnormalities involving the entire left ventricle. Several studies have emphasized the relevance of gated SPECT in LBBB patients by evaluating the enddiastolic images [1719]. Inanir et al. [17] evaluated the diagnostic role of dipyridamole Tc-99 $\mathrm{m}$ sestamibi gated SPECT in 20 patients with LBBB without known coronary artery disease. Angiographic findings correlated best with those of end-diastolic images, indicating that enddiastolic images can significantly reduce artifactual defects in patients with LBBB. Demir et al. [18] showed that gated SPECT imaging, in particular the end-diastolic images, revealed fewer false positive 
results in patients with LBBB. Also Afzal et al. [19] showed that patients with LBBB reduced septal thickening resulted in artifactual septal perfusion defects. Consequently, gating the perfusion scintigraphy and reporting perfusion status on end-diastolic frames in LBBB patients may eliminate artifacts in the septal wall.

In the current issue of the International Journal of Cardiovascular Imaging, Nichols et al. [20] tried to assess which asynchrony parameter derived from gated SPECT systolic wall thickening data best distinguishes LBBB patients from normal subjects. Emory Cardiac Toolbox algorithms were used to compute left ventricular global and regional function and perfusion indices with regional contraction phases for 20 patients with LBBB, and in nine control subjects. Z-score asynchrony measures were derived for phases sampled using the conventional 17-segment model. Z-scores are dimensionless parameters computed as the difference between phase standard deviation minus mean phase standard deviation for a normal population. In the normal subjects contraction occurred nearly simultaneously in all segments, while LBBB patients showed a wide variety of heterogeneous contraction patterns. Zscores most strongly discriminated LBBB patients from control patients (93\% correctly predicted).

Evaluation of asynchrony/dyssynchrony parameters is clinically a very relevant issue in LBBB patients who are being considered for cardiac resynchronization therapy (CRT). Many studies have already observed left ventricular dyssynchrony in LBBB patients with heart failure for whom CRT with biventricular pacing has been shown to be beneficial, particularly when left ventricular ejection fraction (LVEF) is $<35 \%$ and QRS duration $>120 \mathrm{~ms}$ [21-26]. However, $20-30 \%$ of patients with congestive heart failure and LBBB who meet criteria for CRT do not derive significant clinical benefit from the procedure. Novel parameters have been sought to predict clinical responsiveness to CRT that are superior to the purely electrocardiographic and LVEF criteria. Although gated SPECT imaging has been widely used to evaluate myocardial perfusion and cardiac function in patients with heart failure, recently more advanced gated SPECT data processing techniques including phase analysis have been employed to evaluate left ventricular synchronicity [27-33]. Henneman et al. [32] studied 75 patients with heart failure, depressed left ventricular function, and wide QRS complex using gated SPECT and two-dimensional echocardiography, including tissue Doppler imaging (TDI). It was shown that left ventricular dyssynchrony assessed from gated SPECT correlated well with dyssynchrony assessed by TDI. The histogram bandwidth and phase standard deviation showed the best correlation with left ventricular dyssynchrony on TDI. The results of this study [32] support the use of phase analysis by gated SPECT to evaluate left ventricular dyssynchrony. Trimble et al. [33] used phase analysis of gated SPECT to examine the relation between myocardial perfusion, degree of electrical dyssynchrony, and degree of SPECT-derived mechanical dyssynchrony in 125 patients with left ventricular dysfunction. It was shown that heart failure patients with perfusion abnormalities or prolonged QRS durations have higher degrees of mechanical dyssynchrony.

To summarize, gated SPECT myocardial imaging can quantify myocardial function, perfusion, and left ventricular dyssynchrony and may help in evaluating LBBB patients for CRT. The study of Nicols et al. [20] adds a new dimension to the already existing dyssynchrony parameters allowing the identification of patients who qualify for CRT.

Open Access This article is distributed under the terms of the Creative Commons Attribution Noncommercial License which permits any noncommercial use, distribution, and reproduction in any medium, provided the original author(s) and source are credited.

\section{References}

1. Cramer MM, De Boeck BW (2007) Three-dimensional echocardiography and left bundle branch block: prime time in cardiology. Neth Heart J 15:87-88

2. Brunekreeft JA, Graauw M, de Milliano PA, Keijer JT (2007) Influence of left bundle branch block on left ventricular volumes, ejection fraction and regional wall motion. Neth Heart J 15:89-94

3. Möller J, Warwick J, Bouma H (2005) Myocardial perfusion scintigraphy with Tc-99 m MIBI in patients with left bundle branch block: visual quantification of the anteroseptal perfusion imaging for the diagnosis of left anterior descending artery stenosis. Cardiovasc J S Afr 16:95-101

4. Bax JJ, Lamb H, Dibbets P et al (2000) Comparison of gated single-photon emission computed tomography with magnetic resonance imaging for evaluation of left ventricular function in ischemic cardiomyopathy. Am J Cardiol 86:1299-1305

5. Langerak SE, Vliegen HW, de Roos A et al (2002) Detection of vein graft disease using high-resolution magnetic resonance angiography. Circulation 105:328-333 
6. Wackers FJ (1997) Myocardial perfusion defects in left bundle branch block: true or false? Fact or artifact? J Nucl Cardiol 4:550-552

7. van der Wall EE, Heidendal GA, den Hollander W, Westera G, Roos JP (1980) I-123 labeled hexadecenoic acid in comparison with thallium-201 for myocardial imaging in coronary heart disease. A preliminary study. Eur J Nucl Med 5:401-405

8. Braun S, van der Wall EE, Emanuelsson S, Kobrin I (1996) Effects of a new calcium antagonist, mibefradil (Ro 405967), on silent ischemia in patients with stable chronic angina pectoris: a multicenter placebo-controlled study. The mibefradil international study group. J Am Coll Cardiol 27:317-322

9. van Lennep JE, Westerveld HT, van Lennep HW, Zwinderman AH, Erkelens DW, van der Wall EE (2000) Apolipoprotein concentrations during treatment and recurrent coronary artery disease events. Arterioscler Thromb Vasc Biol 20:2408-2413

10. Tandoğan I, Yetkin E, Yanik A et al (2001) Comparison of thallium-201 exercise SPECT and dobutamine stress echocardiography for diagnosis of coronary artery disease in patients with left bundle branch block. Int J Cardiovasc Imaging 17:339-345

11. America YG, Bax JJ, Dibbets-Schneider P, Pauwels EK, Van der Wall EE (2005) Evaluation of the quantitative gated SPECT (QGS) software program in the presence of large perfusion defects. Int J Cardiovasc Imaging 21:519-529

12. Jukema JW, van der Wall EE, van der Vis-Melsen MJ, Kruyswijk HH, Bruschke AV (1993) Dipyridamole thallium-201 scintigraphy for improved detection of left anterior descending coronary artery stenosis in patients with left bundle branch block. Eur Heart J 14:53-56

13. America YG, Bax JJ, Boersma E, Stokkel M, van der Wall EE (2007) Prognostic value of gated SPECT in patients with left bundle branch block. J Nucl Cardiol 14:75-81

14. Bavelaar-Croon CD, Wahba FF, Van Hecke MV et al (2001) Perfusion and functional abnormalities outside the septal region in patients with left bundle branch block assessed with gated SPECT. Q J Nucl Med 45:108-114

15. Bavelaar-Croon CD, Kayser HW, van der Wall EE et al (2000) Left ventricular function: correlation of quantitative gated SPECT and MR imaging over a wide range of values. Radiology 217:572-575

16. Bavelaar-Croon CD, Pauwels EK, van der Wall EE (2001) Gated single-photon emission computed tomographic myocardial imaging: a new tool in clinical cardiology. Am Heart J 141:383-390

17. Inanir S, Caymaz O, Okay $\mathrm{T}$ et al (2001) Tc-99 m sestamibi gated SPECT in patients with left bundle branch block. Clin Nucl Med 26:840-846

18. Demir H, Erbay G, Kir KM, Omurlu K, Berk F, Aktolun C (2003) Clinical validation of technetium-99 m MIBI-gated single-photon emission computed tomography (SPECT) for avoiding false positive results in patients with left bundle-branch block: comparison with stress-rest nongated SPECT. Clin Cardiol 26:182-187

19. Afzal MS, Imran MB, Aslam N et al (2006) Gated spect myocardial perfusion scintigraphy for identifying septal perfusion artifacts in left bundle branch block. J Coll Physicians Surg Pak 16:504-508
20. Nichols KJ, Van Tosh A, Siddiqi S et al (2008) Gated myocardial perfusion SPECT asynchrony measurements in patients with left bundle branch block. Int J Cardiovasc Imaging. doi:10.1007/s10554-008-9354-9

21. Bax JJ, Bleeker GB, Marwick TH et al (2004) Left ventricular dyssynchrony predicts response and prognosis after cardiac resynchronization therapy. J Am Coll Cardiol 44:1834-1840

22. Bax JJ, Marwick TH, Molhoek SG et al (2003) Left ventricular dyssynchrony predicts benefit of cardiac resynchronization therapy in patients with end-stage heart failure before pacemaker implantation. Am J Cardiol 92:1238-1240

23. Bleeker GB, Kaandorp TA, Lamb HJ et al (2006) Effect of posterolateral scar tissue on clinical and echocardiographic improvement after cardiac resynchronization therapy. Circulation 113:969-976

24. Bleeker GB, Schalij MJ, Nihoyannopoulos P et al (2005) Left ventricular dyssynchrony predicts right ventricular remodeling after cardiac resynchronization therapy. J Am Coll Cardiol 46:2264-2269

25. Molhoek SG, Bax JJ, Bleeker GB et al (2004) Comparison of response to cardiac resynchronization therapy in patients with sinus rhythm versus chronic atrial fibrillation. Am J Cardiol 94:1506-1509

26. Molhoek SG, Bax JJ, Bleeker GB et al (2005) Long-term follow-up of cardiac resynchronization therapy in patients with end-stage heart failure. J Cardiovasc Electrophysiol 16:701-707

27. Chen J, Henneman MM, Trimble MA et al (2008) Assessment of left ventricular mechanical dyssynchrony by phase analysis of ECG-gated SPECT myocardial perfusion imaging. J Nucl Cardiol 15:127-136

28. Marsan NA, Henneman MM, Chen J et al (2008) Real-time three-dimensional echocardiography as a novel approach to quantify left ventricular dyssynchrony: a comparison study with phase analysis of gated myocardial perfusion single photon emission computed tomography. J Am Soc Echocardiogr 21:801-807

29. van Ramshorst J, Atsma DE, Beeres SL et al (2008) The effect of intramyocardial bone marrow cell injection on left ventricular dyssynchrony and global strain. Heart 94: 1214-1226

30. Ypenburg C, Schalij MJ, Bleeker GB et al (2007) Impact of viability and scar tissue on response to cardiac resynchronization therapy in ischaemic heart failure patients. Eur Heart J 28:33-41

31. Ajmone Marsan N, Henneman MM, Chen J et al (2008) Left ventricular dyssynchrony assessed by two-threedimensional imaging modalities: phase analysis of gated myocardial perfusion SPECT and tri-plane tissue Doppler imaging. Eur J Nucl Med Mol Imaging 35:166-173

32. Henneman MM, van der Wall EE, Ypenburg C et al (2007) Nuclear imaging in cardiac resynchronization therapy. J Nucl Med 48:2001-2010

33. Trimble MA, Borges-Neto S, Honeycutt EF et al (2008) Evaluation of mechanical dyssynchrony and myocardial perfusion using phase analysis of gated SPECT imaging in patients with left ventricular dysfunction. J Nucl Cardiol 15:663-670 